\title{
FDA Pharmaceutical Quality/CMC Terminology
}

National Cancer Institute

\section{Source}

National Cancer Institute. FDA Pharmaceutical Quality/CMC Terminology. NCI

Thesaurus. Code C133805.

A category of terminology used to qualify the information pertaining to Pharmaceutical Quality/Chemistry, Manufacturing and Controls. 